\title{
ANALISA KERUSAKAN DIES HAMMER FORGING MATERIAL SKT4 UNTUK PROSES PRODUKSI UNDER BRACKET
}

\author{
$\operatorname{Adin}^{1}$ \\ ${ }^{1}$ Program Studi Teknik Mesin, Universitas Pamulang, Jl. Surya Kencana No. 1, Tangerang Selatan, Indonesia \\ E-mail :dosen01285@unpam.ac.id \\ Masuk : 5 Maret 2020 \\ Direvisi : 18 Maret 2020 \\ Disetujui : 24 Maret 2020
}

\begin{abstract}
Abstrak ; Forging merupakan salah satu proses pengerjaan logam yang dilakukan dengan cara merbah bentuk material logam dengan memberikan gaya tekan melalui cetakan die sampai terjadi deformasi plastis pada material. Gaya tekan akan merubah bentuk serta dimensi benda kerja secara permanent mengikuti profil yang ada pada cetakan.Faktor yang melatar belakangi terjadinya kerusakan pada dies dipengaruhi oleh gaya dan tegangan yang bekerja, serta struktur dan kekerasan material dies tersebut. Dilakukan pengujian untuk memastikan penyebab kerusakan, meliputi pengujian struktur mikro,komposisi kimia, dan uji kekerasan. Hasil pengujian diperoleh bahwa kerusakan dies, disebabkan adanya material las pada dies. Selain gaya dan tegangan serta pembebanan yang berlebih. Awal kerusakan berada pada material dies yang berhubungan langsung dengan beban statis dan terdapat material las di bagian tersebut.
\end{abstract}

Kata kunci: dies,forging, kerusakan, pengujian,

\begin{abstract}
Forging is a one process processing metal which is conducted in a way change shape materialby giving pressure who throughdie mold. Until it happened depormation plastic on material compressiveforce will change shape as well as dimensions work permanently follow fropil which is under pressure. The factors behind the occurrence of damage to the dies are influenced by the force and working voltage,as well as structure and hardness of the dies material. Tests are performed to ascertain the cause of the damage,including microstructur observation, testing of chemicalcomposition, and hardnes testing. Test result obtained that the damageto the dies, caused by the welding material on the dies.In addition to force and tension as wellas overloading. The initial damage is to the dies material that is directly related to the static load and there is a welding material in the section.
\end{abstract}

Keywords ; dies, forging, damage, testing.

\section{PENDAHULUAN}

Proses tempa (forging) salah satu proses pengerjaan logam yang dilakukan dengan cara merbah bentuk material logam dengan memberikan gaya tekan melalui cetakan die sampai terjadi deformasi plastis pada material. Gaya tekan akan merubah bentuk serta dimensi benda kerja secara permanent mengikuti profil yang ada pada cetakan.

Dalam proses penempaan logam ada beberapa hal yang harus menjadi perhatian untuk mencapai efisiensi dalam proses produksi dan kualitas produk yang dihasilkan yaitu mendesain cetakan die dan proses produksi. Untuk disain cetakan harus sesuai dengan klasifikasi dari material yaitu material yang dikhususkan untuk cetakan die harus memiliki kekuatan dan ketahanan yang baik seperti mempunyai kekerasan yang 
tinggi,keuletan dan ketahanan terhadap temperature tinggi,disamping tergantung akan hal tersebut diatas juga bagaimana agar cetakan dapat bertahan lama. Sementara proses produksi memperhatikan geometri dan kondisi internal produk yang akan dikerjakan, sebagai contoh adalah aliran logam (metal flow)

Berdasarkan penelitian sebelumnya diperoleh beberapa variable utama yang berperan dalam proses pembentukan tempa yaitu temperature, tekanan, kecepatan pemukulan dan pendinginan serta pelumasan yang diberikan terhadap cetakan die. Variable utama ini memberi kontribusi yang besar terhadap tingkat kerusakan (failure), keausan (wearing) atau cacat (defect) lainnya pada proses penempaan dan pada cetakan [1].

Dalam kaitannya dengan kerusakan dies pada proses penempaan (forging) dengan material die SKT 4. Kerusakan yang terjadi pada umumnya retak, Keropos dan yang paling fatal terjadinya die pecah dua atau pecah beberapa bagian, sementara kerusakan yang sering dialami adalah terjadinya keausan di bagian profil die yang mengakibatkan produk hasil forging menjadi tidak sesuai standard atau NG, sehingga jika kerusakan tersebut tidak ditanggulangi maka akan menghambat proses produksi di perusahaan.

\section{METODOLOGI}

[2]:

Dalam penelitian ini pengumpulan dan analisa data dilakukan dengan beberapa metode sebagai berikut

1) Identifikasi Masalah dan Pengumpulan Data

Pengumpulan data primer dan pendukung dilakukan dengan cara inspeksi lapangan, pengambilan data operasi, pengambilan material dan pemeriksaan kerusakan dies secara visual.

2) Studi Literatur, Pengamatan dan Pengujian

Dalam penelitian penyebab terjadinya kerusakan dari die ini dilakukan beberapa pengamatan dan pengujian di sesuaikan dengan berbagai pustaka maupun literature yang terkait dengan obyek penelitan yang bertujuan untuk mencari penyebab yang terjadi kerusakan dies tersebut berdasarkan analisa struktur mikro, analisa komposisi kimia dan pengujian kekerasan.

\section{HASIL DAN PEMBAHASAN}

Berdasarkan data yang diperoleh dari hasil pengamatan dan pengujian - pengujian yang telah dilakukan, pemilihan material baja hot work jenis SKT4 JIS di yakini tepat sesuai dengan rekomendasi pembuat mesin (maker machine). Jika dalam aplikasinya umur pakai die tidak bisa maksimal perlu dilakukan pengkajian lanjutan dalam proses manufaktur / pembuatan serta operasional pemakainnya.

\section{Analisa Penyebab dan Mekanisme Kerusakan}

\section{Analisa Struktur Mikro}

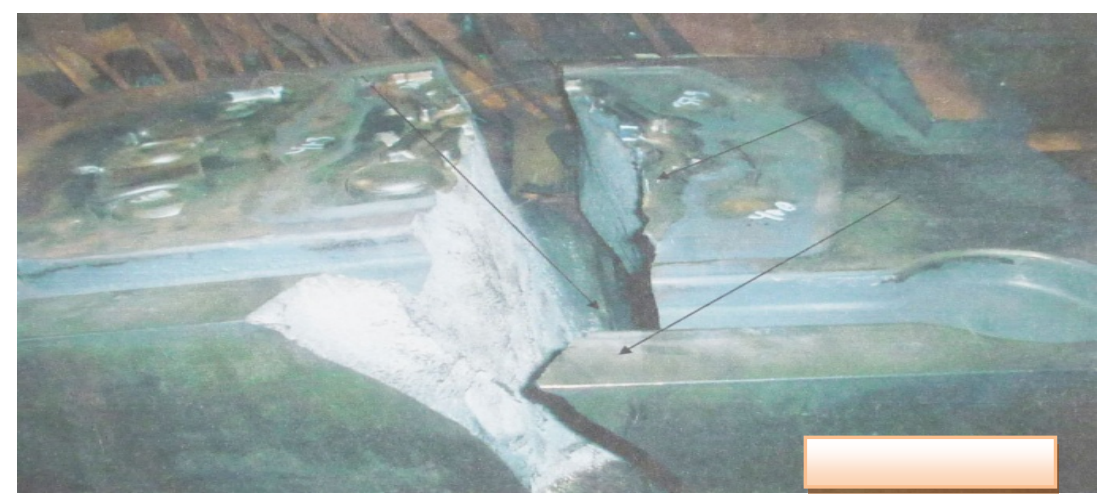

Gambar 1. Photo makro Dies under bracket mengalami retak pada bagian atas.

Penampilan dari permukaan arah patah mempunyai bentuk patah statik,hal ini dapat dilihat dari adanya sudut patah. Pada gambar 1 terlihat die yang mengalami kerusakan setelah produksi,dimana die tersebut pecah menjadi dua bagian. Kerusakan terjadi pada die bawah yang mana saat die mengalami kerusakan sekitar 5 jam setelah die beroperasi. 


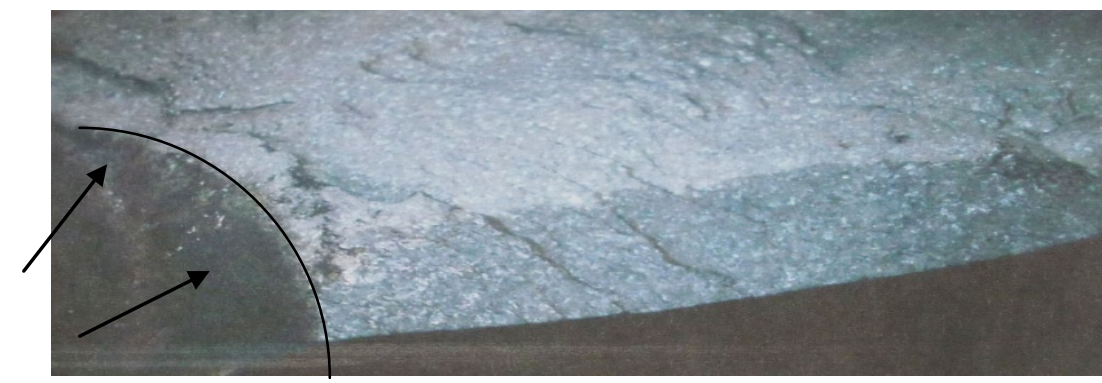

Gambar 2. Indikasi awal patah ditemukan pada bagian atas yaitu daerah yang tidak meneriman benturan akan tetapi menerima beban bending saat bekerja.

Pada gambar 2 terlihat patahan pertama pada saat die mengalami kerusakan. Tanda panah menunjukan arah terjadinya retakan awal yang mengakibatkan die menjadi pecah. Pada daerah ini juga diduga adanya material las yang membuat die tersebut mengalami keretakan awal hingga terjadi retak yang lebih parah sehingga mengakibatkan die pecah.
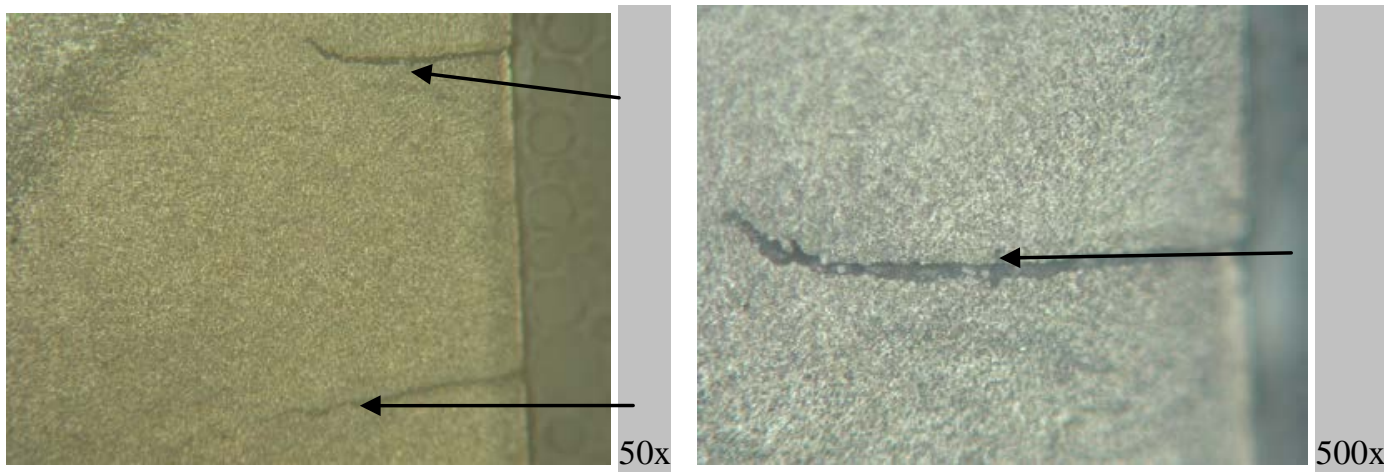

Gambar 3. Retak lainnya pada daerah HAZ halus berupa transgrannular crackings. Etsa:nital 2\% dan Kalling reagent.

Retak pada daerah HAZ yang berupa retakan halus transgrannular ini yang mengakibatkan kerusakan yang lebih besar pada material dies, retakan yang sudah terjadi setelah dilakukan pengelasan akan menjalar ke daerah lain yang lebih luas diakibatkan dari beban statis dari penempaan logam panas yang terjadi dalam proses produksi [3].

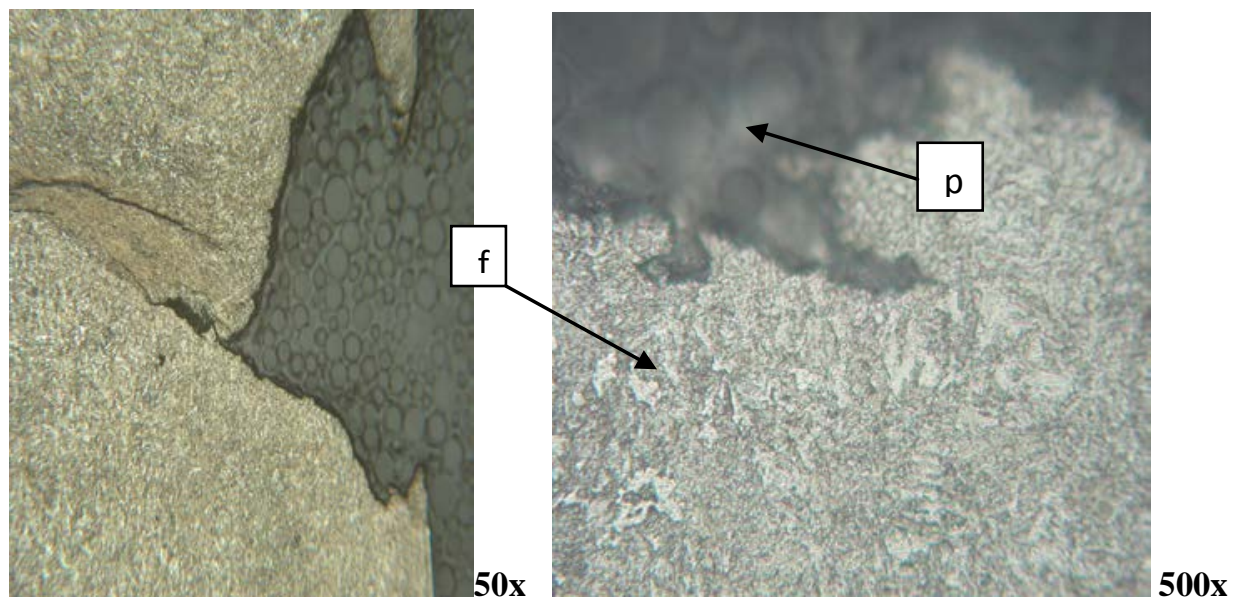

Gambar 4 Struktur mikro daerah patah berupa bainit-ferit. Etsa:nital 2\% 
Bentuk yang terlihat pada gambar 4 tersebut hasil dari pembesaran 500 kali. Pada gambar terlihat terdapat ferrite (F) dan pearlite (P). Struktur yang berwarna terang atau putih adalah struktur ferrite, sedangkan struktur yang berwarna gelap atau hitam adalah struktur pearlite. Struktur ferrite memiliki sifat yang lunak dan liat, memiliki ukuran butir yang besar dan tampak terlihat kasar[4]

\section{Analisa Komposisi Kimia}

Berdasarkan hasil pemeriksaan visual,dipandang perlu untuk melakukan uji komposisi kimia. Tabel dibawah adalah hasil uji komposisi kimia pada material die SKT4 dan didapat data pengujian sebagai berikut ;

Tabel 1 Data pengujian komposisi kimia

\begin{tabular}{|l|c|}
\hline \multirow{2}{*}{ Unsure } & R e s u l t (wt \% ) \\
\cline { 2 - 2 } & \multicolumn{2}{|c|}{ Dies } \\
\hline \multirow{2}{*}{$\mathrm{Fe}$} & 94.4 \\
\hline $\mathrm{C}$ & 0.514 \\
\hline $\mathrm{Si}$ & 0.291 \\
\hline $\mathrm{Mn}$ & 0.838 \\
\hline $\mathrm{Cr}$ & 1.39 \\
\hline $\mathrm{Ni}$ & 1.66 \\
\hline $\mathrm{Mo}$ & 0.393 \\
\hline $\mathrm{Cu}$ & 0.0255 \\
\hline $\mathrm{Al}$ & 0.0339 \\
\hline $\mathrm{V}$ & 0.103 \\
\hline $\mathrm{Ti}$ & 0.0016 \\
\hline $\mathrm{S}$ & 0.0040 \\
\hline $\mathrm{P}$ & 0.0348 \\
\hline $\mathrm{Co}$ & 0.0255 \\
\hline $\mathrm{Nb}$ & 0.0655 \\
\hline $\mathrm{Zr}$ & 0.0051 \\
\hline $\mathrm{Pb}$ & 0,0253 \\
\hline $\mathrm{W}$ & 0.0913 \\
\hline
\end{tabular}

Berdasarkan Tabel 1 diatas dapat dilihat komposisi kimia material die SKT4 yang mengalami kerusakan. Unsur karbon (C) pada Termal shield baru $(0,51 \%$ C) sesuai dengan standar JIS SKT4 (0.5 0.6\%C), komposisi karbon yang standar untuk material hot work sehingga material layak untuk digunakan sebagai bahan baku pembuatan dies. Unsur silikon ( $\mathrm{Si}$ ) pada material die (0,29\%Si) sesuai dengan standar JIS SKT4 (O,10-0,40\%Si), Usur Si pada material sudah masuk standart sehingga ketahanan material untuk hot work bias di pergunakan. Unsur sulfur (S) pada material dies $(0.004 \% S)$ sesuai dengan standar JIS SKT4 (0.005\%S) $\mathrm{S}$ lebih rendah dari standart, dengan rendahnya unsur sulfur (S) pada material dies maka akan mempengaruhi sifat mampu mesin dan sifat kekerasannya. Unsur mangan (Mn) pada Thermal shield baru (0.838\%Mn) sesuai dengan standar JIS SKT4 (0.6 - 0.9\%Mn), sudah masuk standar sehingga material tahan pada temperatur tinggi. Unsur phosfor $(\mathrm{P})$ pada material dies baru $(0.0348 \% \mathrm{P})$ sesuai dengan standar JIS SKT4 $(0.025 \% \mathrm{P}$ max),lebih tinggi sehingga mempengaruhi terbentuknya fasa ferit dan meningkatkan ketahanan korosi dan oksidasi. Unsur Besi (Fe) pada material dies (94.4\%Fe) sesuai dengan standar JIS SKT4 (94.4\%Fe), merupakan dominasi / material utama sehingga akan terpengaruh komposisinya jika unsur - unsur lainnya (Ni, Cr, Mo, V, $\mathrm{Cu}, \mathrm{W}, \mathrm{Ti}, \mathrm{Sn}, \mathrm{Al}, \mathrm{Pb}, \mathrm{Nb}, \mathrm{Zr}, \mathrm{Co})$ berubah. 


\section{Analisa Kekerasan}

Analisa kekerasan pada material dies bagian dalam dimaksudkan untuk menganalisa perubahan kekerasan akibat panas yang diterima. Sampel uji kekerasan diambil masing-masing pada daerah yang mengalami kerusakan dan daerah yang masih normal.Uji kekerasan tersebut menggunakan metode Vickers (ASTM E 10-98)dengan beban 5Kgf dan sudut indentor $136^{\circ}$

Tabel 2: Hasil Uji Kekerasan

\begin{tabular}{|c|c|c|c|}
\hline \multirow{2}{*}{ NO. } & \multicolumn{3}{|c|}{ NILAI KEKERASAN, HV } \\
\cline { 2 - 4 } & Sampel 1 & Sampel 2 & Sampel 3 \\
\hline 1 & 700 & 396 & 401 \\
\hline 2 & 699 & 401 & 349 \\
\hline 3 & 396 & 401 & 328 \\
\hline 4 & 381 & 396 & 386 \\
\hline 5 & 391 & 407 & 407 \\
\hline 6 & 396 & 386 & 407 \\
\hline 7 & 390 & 401 & 407 \\
\hline 8 & 381 & 401 & 404 \\
\hline 9 & 386 & 391 & 400 \\
\hline 10 & 386 & 391 & 400 \\
\hline
\end{tabular}

Dari tabel diatasdapat diketahui nilai kekerasan pada permukaan material die tiap sampel dengan lokasi uji 10 titik yaitu sampel 1 hasil maksimal pengukuran kekerasan berada di titik 1 dengan nilai 700 dan nilai terendah berada di titik 8 dengan nilai 381.Sampel 1 ini di ambil dari daerah yang tidak terpengaruh panas langsung. Sampel 2 hasil maksimal pengukuran kekerasan berada di titik 5 dengan nilai 407 dan nilai terendah di titik 9 dan 10 dengan nilai 391. Sampel 3 hasil pengukuran kekerasan berada di titik 5,6 dan 7 dengan nilai 407 dan nilai terendah di titik3 dengan nilai 329.

\section{Analisa Hasil Pengujian}

Dari hasil pengamatan visual,Pengujian komposisi kimia,Pengujian kekerasan, dan Pengujian struktur mikro. dapat diketahui perubahan - perubahan yang sangat signifikan antara material die kondisi rusak dengan melihat hasil pengujian diatas, terlihat kondisi rusak pada sifat mekanis maupun sifat lainnya. Hal ini dimungkinkan karena tekanan beban dan pemanasan konstan $\pm 1.100^{\circ} \mathrm{C}$ secara terus menerus sehingga menyebabkan terjadinya perbedaan temperatur pada material die yang bawah dan atas yang terpasang pada penutup mesin forging hammer 2 ton, dan dengan ditemukan nya material las pada die yang mengalami kerusakan memperkuat hasil pengujian bahwa factor utama terjadinya kerusakan (dies pecah) adalah factor pengelasan material die yang dilakukan sebelum dis di operasikan, hal inilah yang membuat terjadinya retak awal pada material dan akibat beban dan suhu panas yang terjadi mengakibatkan die pecah dengan analisa patah rapuh.

\section{KESIMPULAN}

Berdasarkan hasil penelitian dan pembahasan dapat disimpulkan bahwa :

1. Pengujian material die, komposisi kimia pada material die telah standar JIS SKT4 sehingga tidak berpengaruh pada kerusakan.

2. Pada pengamatan visual dan hasil pengujian terhadap kerusakan die yang terjadi berupa kerusakan patah getas (stress cracking) pada material die akibat adanya tegangan sisa hasil las.

3. Berdasar hasil inspeksi visual dan pengujian material die patah intergranular/kerusakan yang terjadi diatas butir pada material dan kerusakan yang terjadi diakibatkan karena beban impek yang terjadi terutama didaerah yang terkena bahan las. 
Adin, Analisa kerusakan die hammer forging material SKT4...,

\section{DAFTAR PUSTAKA}

1. M.Arentoft and T. Wanheim, 2000, "The basis for a design support system to prevent defect in forging”, Journal of Materials Processing Technology 69

2. D,N. Adnyana, Struktur dan Sifat Mekanis Material Logam, Diktat Mata Kuliah Program Pasca Sarjana (S2) ISTN Jakarta, 2003.

3. Amanto Hari., \& Daryanto. (2003). Ilmu Bahan. Jakarta : PT. Bumi Akasara.

4. Daryanto, IlmuMetalurgy.Satunusa, Bandung, Oktober 2010 